\title{
Efficacy of cisplatin plus vinorelbine adjuvant chemotherapy with split-dose administration of cisplatin after complete resection of stage II-IIIA non-small cell lung cancer
}

\author{
NORIHIKO FUNAGUCHI ${ }^{1,2}$, HIROTOSHI IIHARA ${ }^{3}$, DAIZO KAITO ${ }^{1}$, TAKENORI GOMYO ${ }^{1}$, \\ YUKA SASAKI $^{1}$, KOMEI YANASE $^{1}$, JUNKI ENDO $^{1}$, FUMITAKA ITO $^{1}$, \\ CHIEMI HIROSE ${ }^{3}$, YASUSHI OHNO ${ }^{1}$ and HIROYUKI OKURA ${ }^{1}$ \\ ${ }^{1}$ Department of Cardiology and Respiratory Medicine, Gifu University Graduate School of \\ Medicine, Gifu 501-1194; ${ }^{2}$ Department of Respirology, Asahi University Hospital, Gifu 500-8523; \\ ${ }^{3}$ Department of Pharmacy, Gifu University Hospital, Gifu 501-1194, Japan
}

Received November 14, 2021; Accepted January 13, 2022

DOI: $10.3892 / \mathrm{mco} .2022 .2509$

\begin{abstract}
Although co-administration of cisplatin (CDDP) and vinorelbine (VNR) has been established as a standard of care adjuvant chemotherapy for non-small cell lung cancer (NSCLC), there is a lack of clinical data on its safety and efficacy in Japanese patients receiving split-dose administration of CDDP. The present study analyzed patients who received CDDP + VNR with split-dose administration of CDDP after undergoing complete resection of NSCLC. Patients received four courses of CDDP $\left(40 \mathrm{mg} / \mathrm{m}^{2}\right)$ and VNR $\left(25 \mathrm{mg} / \mathrm{m}^{2}\right)$ on days 1 and 8 , every 3 weeks. There were 27 male and 13 female patients; the mean age was 65 years (range 38-78 years), the postoperative disease staging distribution was IIA/IIB/IIIA: 14/8/18 patients, and histological distribution was adenocarcinoma/squamous cell carcinoma/others: 24/12/4 patients, respectively. Of the 40 patients, $28(70 \%)$ completed the four courses of treatment. The mean total dose administered was $279 \mathrm{mg} / \mathrm{m}^{2} \mathrm{CDDP}(87.2 \%)$ and $172 \mathrm{mg} / \mathrm{m}^{2} \mathrm{VNR}(86 \%)$. The major adverse events included Grade (G) 3 or higher neutropenia (80\%), G3 phlebitis (5\%) and vomiting (2.5\%). There was no G2 or higher serum creatinine level elevation, G3 or higher anorexia and nausea, or any treatment-related deaths. The overall completion rate of four courses was 70 and $62.5 \%$ for patients aged 70 years and older, whereas the overall percentage of patients that could complete three or more courses was 85 and $87.5 \%$ for patients aged 70 years and older. The relapse-free survival rate was $60 \%$ at 3 years and $57.5 \%$ at 5 years. Overall survival rate was $80 \%$ at 3 years and $60 \%$
\end{abstract}

Correspondence to: Dr Norihiko Funaguchi, Department of Respirology, Asahi University Hospital, 3-23 Hashimoto-cho, Gifu 500-8523, Japan

E-mail: funa2im@yahoo.co.jp; funanori@hosp.asahi-u.ac.jp

Key words: non-small cell lung cancer, adjuvant chemotherapy, cisplatin, vinorelbine, split-dose at 5 years. The present study demonstrated the sufficient tolerability, safety and efficacy of combined CDDP + VNR adjuvant chemotherapy with split-dose administration of CDDP, with a low risk of gastrointestinal toxicities or nephrotoxicity.

\section{Introduction}

The 5-year survival rate for non-small cell lung cancer (NSCLC) in Japan is $54.5 \%$ for stage IIA disease, $46.4 \%$ for stage IIB disease and $42.8 \%$ for stage IIA disease (1), and it is difficult to say whether treatments are sufficiently effective. As recurrence in patients undergoing surgery often tends to be distal metastatic recurrence, it is important to control micrometastases by adjuvant chemotherapy. In 1995, the Non-small Cell Lung Cancer Collaborative Group reported a meta-analysis of a randomized controlled trial that compared surgery monotherapy vs. surgery + adjuvant chemotherapy, which indicated that the use of adjuvant chemotherapy involving combined administration of cisplatin (CDDP) reduced the relative mortality risk rate by $13 \%$, and improved the 5-year survival rate by $5 \%$, although without a significant difference (2). Thereafter, comparative trials, such as The International Adjuvant Lung Cancer Trial Collaborative Group (IALT), The National Cancer Institute of Canada JBR.10 trial (JBR.10) and the Adjuvant Navelbine International Trial Association (ANITA) trial etc., were carried out, and in each study the progression-free survival rate and 5-year survival rate improved when patients were administered adjuvant chemotherapy that included CDDP co-administration (3-7). In JBR.10, the prognosis of patients who received adjuvant chemotherapy using CDDP and vinorelbine (VNR) for stage IB or II disease was $15 \%$ better than those who underwent only surgery (without adjuvant chemotherapy). The ANITA study demonstrated the additive effect of CDDP and VNR co-administration for stage IB to IIIA disease after surgery, with an improvement in the 5 -year survival rate by $8.6 \%$. The Lung Adjuvant Cisplatin Evaluation (LACE) meta-analysis showed the improved hazard ratio (HR) for survival after surgery [0.89 (95\% confidence interval [CI]: 0.82 to 0.96$)$ ] 
and significant prolongation of lifespan owing to adjuvant chemotherapy. The HR according to disease staging was 0.83 for stage II (95\% CI: 0.73 to 0.95$)$ and 0.83 for stage III $(95 \%$ CI: 0.72 to 0.94$)(8)$. A subgroup meta-analysis limited to CDDP + VNR indicated an HR of 0.80 (95\% CI: 0.70 to 0.91$)$, and the improvement in survival by CDDP + VNR relative to surgery alone was remarkable, at 43 to $54 \%$ in stage II disease and 25 to $40 \%$ in stage III disease (9). These studies from other countries showed that combined CDDP + VNR regimens contributed to prolongation of survival, making it the regimen with the highest evidence level to date (10); however, there are very few reports regarding the safety and efficacy of adjuvant chemotherapy involving co-administration of CDDP and VNR in Japanese patients. In addition, even though reports indicate that split dose administration of CDDP can achieve similar dose intensities as bulk administration while only causing mild side effects (11), it is difficult to say that its efficacy and usefulness has been thoroughly evaluated.

Therefore, in this study, we administered combined CDDP + VNR adjuvant chemotherapy with split-dose CDDP administration to patients of NSCLC, with postoperative disease staging of II to IIIA, who had undergone complete resection, and retrospectively evaluated the safety and efficacy of the chemotherapy regimen. The chemotherapy regimen was administered every 3 weeks (one course) for a target total of four courses, where CDDP $40 \mathrm{mg} / \mathrm{m}^{2}$ and VNR $25 \mathrm{mg} / \mathrm{m}^{2}$ were administered on days 1 and 8 .

\section{Materials and methods}

Study design and setting. We analyzed patients who received CDDP + VNR with split-dose administration of CDDP after undergoing complete resection of NSCLC during the 8 years between October 2007 to September 2015 at the Department of Respiratory Medicine, Gifu University Hospital, Japan. The patients had undergone complete resection of NSCLC of stage IIA to IIIA (UICC 7th Edition), and met the following inclusion criteria: i) 18 years or older, ii) Eastern Cooperative Oncology Group (ECOG) performance status (PS) of 0 or 1, and iii) well-maintained bone marrow, liver, kidney and lung function. Patients with serious complications (e.g., serious heart condition, interstitial pneumonia, infections, poorly-controlled diabetes/hypertension etc.) were excluded from the study. The study was conducted with the approval of the Gifu University Graduate School of Medicine Ethics Committee (approval No. 2021-A055). In view of the retrospective nature of the study, informed consent from the subjects was not mandated.

Treatment. Treatment schematic diagram for this study is shown in Fig. 1. The patients were administered CDDP $40 \mathrm{mg} / \mathrm{m}^{2}$ and VNR $25 \mathrm{mg} / \mathrm{m}^{2}$ on days 1 and 8 by intravenous infusion every 3 weeks (one course), for a target total of four courses. VNR was intravenously infused over $5 \mathrm{~min}$ after dissolving in $50 \mathrm{ml}$ of physiological saline, and the infusion line was later flushed with $250 \mathrm{ml}$ of physiological saline. CDDP was dissolved in $500 \mathrm{ml}$ of physiological saline and intravenously infused over 90 min after VNR administration. As an antiemetic measure, intravenous infusion of 5-HT3 receptor antagonist and dexamethasone $(9.9 \mathrm{mg}$ ) were administered on day 1 , followed by the treatment with oral dexamethasone ( $4 \mathrm{mg} / \mathrm{day})$ on days 2 and 3. In the event of G4 neutropenia, as the first step, the VNR dose was reduced to $20 \mathrm{mg} / \mathrm{m}^{2}$, and as a second step, the CDDP dose was reduced to $30 \mathrm{mg} / \mathrm{m}^{2}$. A total of $2,000 \mathrm{ml}$ of hydration was provided on day 1 .

Assessment of patients. Hematological toxicities (neutropenia, leukopenia, anemia, thrombocytopenia, febrile neutropenia, liver and kidney injuries) and non-hematological toxicities (nausea/vomiting, anorexia, constipation, hiccup, phlebitis) were evaluated based on the Common Terminology Criteria for Adverse Events (CTCAE) version 4.0, using the electronic medical chart records maintained by physicians, nurses and pharmacists, as well as each patient's clinical laboratory test results. The dosing status and treatment completion rate of CDDP and VNR were evaluated. The actual dose administered was evaluated based on the scheduled total doses of CDDP and VNR over four courses, of 320 and $200 \mathrm{mg} / \mathrm{m}^{2}$, respectively. Furthermore, in order to evaluate of efficacy and prognosis, confirmation and analysis of recurrence and survival was carried out on September 30, 2020. The Kaplan-Meier method was used to analyze the relapse-free survival (RFS) from the date of surgery to the date of recurrence or the date of last follow-up, as well as overall survival (OS) from the date of surgery to the date of death or the date of last follow-up. EGFR gene mutation analysis was conducted using the Cycleave polymerase chain reaction method after collecting tumors from the paraffin-embedded sections of the lung cancer specimens and extracting their DNA.

Statistical analysis. The survival curves were estimated using the Kaplan-Meier method, and differences were evaluated using the Mantel-Cox log rank test. The data were analyzed using SPSS version 11 (SPSS Inc.) and GraphPad Prism version 6.0 (GraphPad software). $\mathrm{P}<0.05$ was considered statistically significant.

\section{Results}

Patient characteristics. A total of 40 patients were enrolled in this study, including 27 men and 13 women. Patient background information is shown in Table I. The median age was 65 years (age distribution: 38 to 78 years old), and the postoperative disease staging distribution was IIA/IIB/IIIA: 14/8/18 patients, respectively. The histological subtypes were such that 24 patients had adenocarcinoma, 12 patients had squamous cell carcinoma and 4 patients had other histologies. The median duration of time between the date of surgery and the date of start of chemotherapy was 47 days (range: 27 to 76 days). The median length of the observation period was 65 months (range: 18 to 145 months).

Side effects. Table II shows the incidences of side effects. In terms of hematological toxicities, 19 patients (47.5\%) experienced Grade $(\mathrm{G}) 4$ neutropenia, 32 patients $(80 \%)$ experienced G3 or higher neutropenia and 2 patients experienced febrile neutropenia. Nine patients $(22.5 \%)$ had G1 elevated serum creatinine levels, but there was no G2 level elevation. In terms of G3 non-hematological toxicity, two patients had phlebitis, and only one patient had episodes of vomiting. There were no treatment-related deaths. 
Table I. Patient characteristics $(n=40)$.

\begin{tabular}{lc}
\hline Characteristic & Number $(\%)$ \\
\hline Sex & \\
Male & $27(68)$ \\
Female & $13(32)$ \\
Age, years & \\
Mean & 65 \\
Range & $38-78$ \\
$<70$ & $32(80)$ \\
$\geq 70$ & $8(20)$ \\
Pathological stage & \\
IIA & $14(35)$ \\
IIB & $8(20)$ \\
IIIA & $18(45)$ \\
Histology & \\
Adenocarcinoma & $24(60)$ \\
Squamous cell carcinoma & $12(30)$ \\
Others & $4(10)$ \\
Surgical procedure & \\
Pneumonectomy & $13(32.5)$ \\
Lobectomy & $23(57.5)$ \\
Bilobectomy & $4(10)$ \\
Others & $35(88)$ \\
Performance status (ECOG) & $3(8)$ \\
0 & $1(2)$ \\
1 & \\
EGFR mutation status & $30(75)$ \\
Positive & $10(25)$ \\
NA & \\
\hline
\end{tabular}

ECOG, Eastern Cooperative Oncology Group; EGFR, epidermal growth factor receptor; NA, not available.

Chemotherapy compliance. Table III shows the results of dosing status. Of the 40 patients, 31 patients received the 4 th course of treatment, but since three patients discontinued treatments on day 8 of the 4 th course, we state that 28 patients $(70 \%)$ completed four courses of treatments. Of the 28 patients who completed the four courses of treatments, eight had reduced their treatment doses, whereas $34(85 \%)$ completed three or more courses. Reasons for not being able to complete all four courses included recurrence in three patients, toxicity in four patients, request to discontinue treatments by four patients and for other reasons in one patient. The median and mean total dose of CDDP administered were 320 and $279 \mathrm{mg} / \mathrm{m}^{2}$ ( $87.2 \%$ of scheduled dose, 80 to $320 \mathrm{mg} / \mathrm{m}^{2}$ ), respectively, and the median and mean total dose of VNR administered were 200 and $172 \mathrm{mg} / \mathrm{m}^{2}$ (86\% of scheduled dose, 50 to $200 \mathrm{mg} / \mathrm{m}^{2}$ ), respectively.

In the subgroup analysis, five of the eight patients aged 70 years or older $(62.5 \%)$ completed four courses, and seven patients $(87.5 \%)$ completed three or more courses. The
Table II. Hematological and non-hematological toxicity $(n=40)$.

\begin{tabular}{lrrrr}
\hline Side effect & G1 & G2 & G3 & G4 \\
\hline Leukopenia & 4 & 13 & 13 & 4 \\
Neutropenia & 1 & 4 & 13 & 19 \\
Anemia & 13 & 23 & 4 & 0 \\
Thrombocytopenia & 24 & 1 & 0 & 0 \\
Febrile neutropenia & - & - & 2 & 0 \\
Anorexia & 17 & 9 & 0 & 0 \\
Nausea & 12 & 13 & 0 & 0 \\
Vomiting & 2 & 3 & 1 & 0 \\
Constipation & 14 & 21 & $0-$ & 0 \\
Hiccoughs & 8 & 4 & 0 & 0 \\
Phlebitis & 1 & 2 & 2 & 0 \\
Increased AST & 10 & 2 & 0 & 0 \\
Increased ALT & 12 & 1 & 0 & 0 \\
Increased creatinine & 9 & 0 & 0 & 0
\end{tabular}

AST, aspartate aminotransferase; ALT, alanine aminotransferase.

median total dose of CDDP in patients aged 70 years or older was $280 \mathrm{mg} / \mathrm{m}^{2}$, and the mean total dose in patients aged 70 years or older was $270 \mathrm{mg} / \mathrm{m}^{2}$ (84.4\% of the planned dose, $160 \sim 320 \mathrm{mg} / \mathrm{m}^{2}$ ). The median total dose of VNR in patients aged 70 years or older was $160 \mathrm{mg} / \mathrm{m}^{2}$, and the mean total dose in patients aged 70 years or older was $165 \mathrm{mg} / \mathrm{m}^{2}(82.5 \%$ of the planned dose, 100 200 mg/m²).

Evaluation of efficacy and prognosis. The Kaplan-Meier curve for RFS is shown in Fig. 2. Median PFS had not been reached, and the RFS rate was $60 \%$ at 3 years and $57.5 \%$ at 5 years. The Kaplan-Meier curve for OS is shown in Fig. 3. Median OS was 108 months, and the OS rate was $80 \%$ at 3 years and $60 \%$ at 5 years. According to the disease stage, the 3 -year RFS rate was $71.4 \%$ for stage IIA disease, $62.5 \%$ for stage IIB disease and $50 \%$ for stage IIIA disease, whereas the 5-year RFS rate was $71.4 \%$ for stage IIA disease, $62.5 \%$ for stage IIB disease and $44.4 \%$ for stage IIIA disease. There was no significant difference in PFS between disease stages (IIA vs. IIB, $\mathrm{P}=0.407$; IIA vs. IIIA, $\mathrm{P}=0.176$; IIB vs. IIIA, $\mathrm{P}=0.757$; II vs. IIIA, $\mathrm{P}=0.257$; data not shown). The 3 -year OS rate was $78.6 \%$ for stage IIA disease, $87.5 \%$ for stage IIB disease and $77.8 \%$ for stage IIIA disease, whereas the 5-year OS rate was $64.3 \%$ for stage IIA disease, $62.5 \%$ for stage IIB disease and $55.6 \%$ for stage IIIA disease (data not shown). Moreover, there was no significant difference in OS between the disease stages (IIA vs. IIB, $\mathrm{P}=0.735$; IIA vs. IIIA, $\mathrm{P}=0.848$; IIB vs. IIIA, $\mathrm{P}=0.799$; II vs. IIIA $\mathrm{P}=0.996$ ) (data not shown). The 3 -year RFS by histology was $45.8 \%$ with adenocarcinomas and $81.3 \%$ with non-adenocarcinomas, and the 5-year RFS was $41.7 \%$ with adenocarcinomas and with $81.3 \%$ non-adenocarcinomas. The 3 -year OS was $83.3 \%$ with adenocarcinomas and $81.3 \%$ with non-adenocarcinomas, and the 5-year OS was $62.5 \%$ with adenocarcinomas and $62.5 \%$ with 


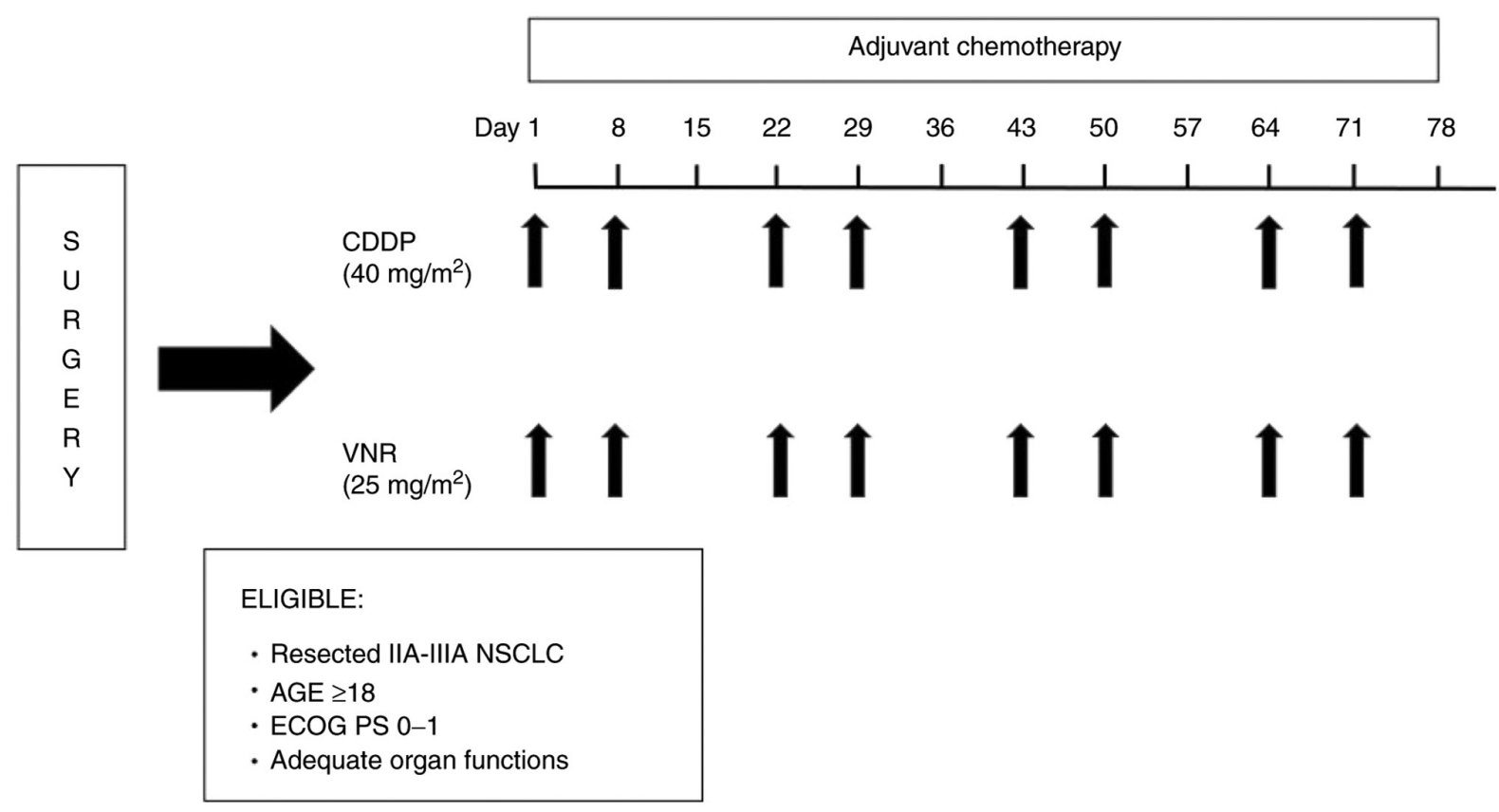

Figure 1. Treatment schematic diagram. NSCLC, non-small cell lung cancer; ECOG, Eastern Cooperative Oncology Group; PS, performance status; CDDP, cisplatin; VNR, vinorelbine.

non-adenocarcinomas; these findings demonstrated that RFS was significantly poorer with adenocarcinomas $(\mathrm{P}=0.015)$, without a significant difference in $\mathrm{OS}(\mathrm{P}=0.969)$. Furthermore, no significant difference in RFS was observed for patients younger or older than 70 years $(\mathrm{P}=0.625)$, with the 3 -year RFS being $59.4 \%$ in patients younger than 70 years and $62.5 \%$ in patients 70 years and older. Likewise, no difference in OS was demonstrated, with the 5-year OS being $62.5 \%$ in patients younger than 70 years and $50 \%$ in those 70 years or older $(\mathrm{P}=0.291)$ (data not shown).

Recurrence occurred in 18 patients $(45 \%)$. According to the postoperative disease stage, recurrence occurred in four patients with stage IIA disease (10\%), four patients with IIB disease $(10 \%)$ and ten patients with stage IIIA disease (25\%). The recurrence sites were lung metastasis in five patients, brain metastasis in five, bone metastasis in five, pleurisy in two, mediastinal lymph nodes in three, and meningitis in one patient (with some overlap).

Treatments after recurrence. The epidermal growth factor receptor (EGFR) gene was found to be mutated in 13 out of 40 patients $(32.5 \%)$. The EGFR gene mutation types was L858R in six patients and exon 19 deletion in seven, and the histology of all EGFR mutation-positive cases was adenocarcinoma. Of the 24 patients with adenocarcinoma, 13 (54.2\%) were positive for EGFR mutation. Of the 18 patients with cancer recurrence, $8(44.4 \%)$ were positive for EGFR mutation, 7 patients used EGFR-tyrosine kinase inhibitors (EGFR-TKIs), and just one patient opted for best supportive care instead of aggressive treatments. The treatments given to EGFR-negative recurrence cases were such that 7 patients received chemotherapy, whereas others underwent brain surgery for metastatic lesions + radiation therapy, thoracic spine metastasis radiation therapy, and resection of metastatic lung lesions.

\section{Discussion}

$\mathrm{CDDP}+\mathrm{VNR}$ is the adjuvant chemotherapy regimen with the highest evidence level for NSCLC, and is therefore widely used in routine clinical practice. The ANITA study administered patients CDDP $100 \mathrm{mg} / \mathrm{m}^{2}$ on day 1 and VNR $30 \mathrm{mg} / \mathrm{m}^{2}$ on days $1,8,15$ and 22 , every 4 weeks (one course) for a total of four courses. The JBR.10 study administered patients with CDDP $50 \mathrm{mg} / \mathrm{m}^{2}$ on days 1 and 8 and VNR $30 \mathrm{mg} / \mathrm{m}^{2}$ on days $1,8,15$ and 22 , every 4 weeks (one course) for a total of four courses. Although both the ANITA and JBR.10 studies planned to administer VNR consecutively for 16 weeks, in reality the dose of VNR administered was around $50 \%$ of the scheduled dose in both studies. Treatment-related deaths occurred in $2 \%$ of patients in the ANITA study and in $0.8 \%$ of patients in the JBR.10 study. Taking these results into consideration, we opted to administer CDDP in split doses according to the regimen of the JBR.10 study, in order to increase the safety and tolerability of the treatment. In terms of the scheduled doses, as the doses of the CDDP + VNR regimen commonly used in Japan for the treatment of NSCLC is CDDP $80 \mathrm{mg} / \mathrm{m}^{2} /$ cycle and VNR $50 \mathrm{mg} / \mathrm{m}^{2} /$ cycle (12), we decided to split administer CDDP $40 \mathrm{mg} / \mathrm{m}^{2}$ on days 1 and 8 , and co-administer VNR $25 \mathrm{mg} / \mathrm{m}^{2}$ on days 1 and 8 , with a single course spanning for 3 weeks, and the treatment was to be repeated for four courses.

The first phase III randomized controlled trial of adjuvant chemotherapy for stage II to IIIA NSCLC in Japan (JIPANG) was carried out, which compared the efficacy of CDDP + VNR against that of CDDP + pemetrexed (PEM) for non-squamous cell carcinoma (13). In the JIPANG study, CDDP $80 \mathrm{mg} / \mathrm{m}^{2}$ was administered on day 1 , whereas $25 \mathrm{mg} / \mathrm{m}^{2}$ was administered on days 1 and 8 , every 3 weeks (one course) for four courses. In the study, Grade 3 or higher leukopenia was observed in $51 \%$ of patients, neutropenia in $81.1 \%$, anemia in $9.3 \%$, and febrile 
Table III. Chemotherapy compliance.

\begin{tabular}{lcc}
\hline Compliance & Cisplatin & Vinorelbine \\
\hline Patients who completed cycles $(\%)$ & & $40(100 \%)$ \\
Cycle 1 & $40(100 \%)$ & $39(97.5 \%)$ \\
Cycle 2 & $39(97.5 \%)$ & $34(85 \%)$ \\
Cycle 3 & $34(85 \%)$ & $28(70 \%)$ \\
Cycle 4 & $28(70 \%)$ & $70 \%$ \\
Four-course-completion rate & & $71.9 \%$ \\
Overall $(\mathrm{n}=40)$ & $70 \%$ & $62.5 \%$ \\
$<70$ years $(\mathrm{n}=32)$ & $71.9 \%$ & $200 \mathrm{mg} / \mathrm{m}^{2}$ \\
$\geq 70$ years $(\mathrm{n}=8)$ & $62.5 \%$ & \\
Planned cumulative dose & $320 \mathrm{mg} / \mathrm{m}^{2}$ & \\
Mean cumulative dose (range) & & $172 \mathrm{mg} / \mathrm{m}^{2}(50-200)$ \\
Overall $(\mathrm{n}=40)$ & $279 \mathrm{mg} / \mathrm{m}^{2}(80-320)$ & $174 \mathrm{mg} / \mathrm{m}^{2}(50-200)$ \\
$<70$ years $(\mathrm{n}=32)$ & $281 \mathrm{mg} / \mathrm{m}^{2}(80-320)$ & $165 \mathrm{mg} / \mathrm{m}^{2}(100-200)$ \\
$\geq 70$ years $(\mathrm{n}=8)$ & $270 \mathrm{mg} / \mathrm{m}^{2}(160-320)$ & \\
Mean relative dose intensity & & $86 \%$ \\
Overall $(\mathrm{n}=40)$ & $87.2 \%$ & $87 \%$ \\
$<70$ years $(\mathrm{n}=32)$ & $87.8 \%$ & $84.4 \%$ \\
$\geq 70$ years $(\mathrm{n}=8)$ & & \\
\hline
\end{tabular}

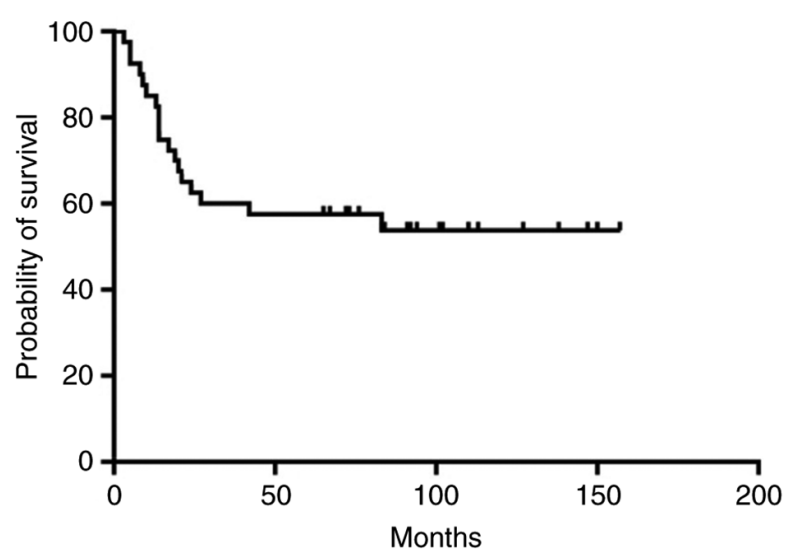

Figure 2. RFS from the date of surgery. The median RFS had not been reached. The RFS rate was $60.0 \%$ at 3 years and $57.5 \%$ at 5 years. RFS, relapse-free survival.

neutropenia in $11.6 \%$ of patients. In the CDDP + VNR arm, the median RFS was 37.3 months and the 3 -year survival rate was $83.5 \%$; the median OS was unavailable. The therapeutic effect of CDDP + VNR for non-squamous cell carcinoma was equivalent to that of CDDP + PEM; thus, the fact that $\mathrm{CDDP}+\mathrm{VNR}$ is one of the adjuvant chemotherapy regimens for NSCLC with the highest evidence level will remain unchanged in the future. In our study, the prevalence of Grade 3 or higher neutropenia was $80 \%$, which was almost the same as in the JIPANG study. In this study, only two patients had febrile neutropenia (5\%), which was less than in the JIPANG study, and there were no treatment-related deaths either. In the JIPANG study, $3.7 \%$ of patients had G3 nausea, $1 \%$ had G3 vomiting and $10.9 \%$ had G3 anorexia, but in our study, we did not observe any G3 nausea and anorexia, which suggests

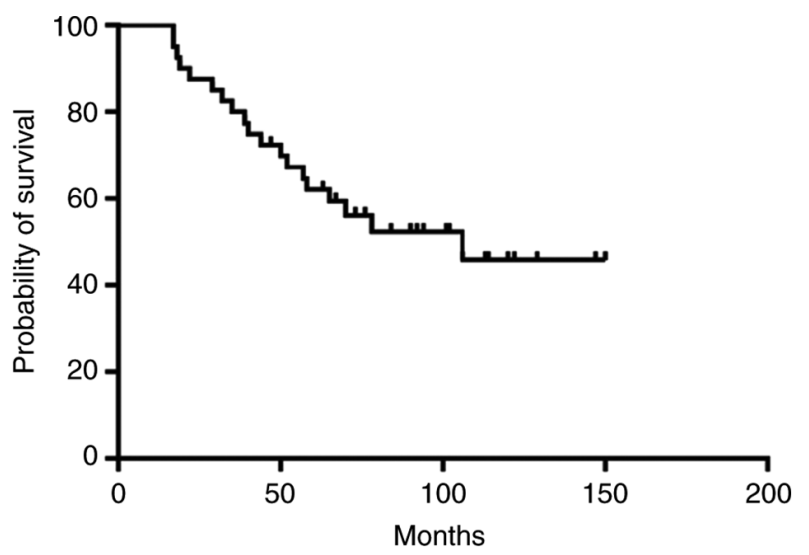

Figure 3. OS from the date of surgery. The median OS was 108 months. The OS rate was $80.0 \%$ at 3 years and $60.0 \%$ at 5 years. OS, overall survival.

that split-dose administration of CDDP may help reduce gastrointestinal toxicities. Furthermore, Kenmotsu et al (14) have published a retrospective analysis on 100 Japanese patients with stage II to IIIA NSCLC who received combined CDDP + VNR treatments with bulk administration of CDDP $80 \mathrm{mg} / \mathrm{m}^{2}$ on day 1 , and reported that $9 \%$ of patients had Grade 2 or higher serum creatinine level elevation, but no such elevation was observed in our study. In addition to proximal tubular damage caused by CDDP, a significant decrease in oral hydration and reduction in circulating plasma volume due to gastrointestinal toxicities, such as nausea, vomiting, and anorexia caused by CDDP, can be mentioned as the mechanisms of kidney damage (15). We surmise that in our study, the risk of kidney damage decreased because of the halving of the quantity of CDDP administered each time by split-dose administration and decrease in gastrointestinal toxicities. 
In our study, 28 out of 40 patients $(70 \%)$ completed four courses of treatments, and 34 patients $(85 \%)$ completed three or more courses of treatments. In the ANITA study and the JBR.10 study, the four-course-completion rate ranged between 45 and $50 \%$. Sonobe et al (16) reported in a phase II study the administration of patients with CDDP $40 \mathrm{mg} / \mathrm{m}^{2}$ and VNR $25 \mathrm{mg} / \mathrm{m}^{2}$ on days 1 and 8 , every 4 weeks (one course), and mentioned that the four-course-completion rate of the 60 patients involved was $47 \%$, but the proportion of patients who could complete three or more courses of treatments was as high as in our study, at $83 \%$. The LACE meta-analysis reported that the OS results were significantly favorable when the total dose of CDDP administered was $300 \mathrm{mg} / \mathrm{m}^{2}$ or higher (8). The median and mean total dose of CDDP in our study were 320 and $279 \mathrm{mg} / \mathrm{m}^{2}$, respectively, and in the subgroup of patients aged 70 years or older, the proportion who completed three or more courses was similar to that in patients younger than 70 years, thus demonstrating that the treatment was well tolerated in the elderly. Hence, we concluded that combined CDDP + VNR adjuvant chemotherapy with split-dose CDDP administration is a method of high treatment completion rate that can administer a sufficient quantity of CDDP.

The therapeutic effect of this study was such that the RFS rate was $60 \%$ at 3 years and $57.5 \%$ at 5 years, OS rate was $80 \%$ at 3 years and $60 \%$ at 5 years, and tumor recurrence occurred in 18 out of 40 patients (45\%). In the subset analysis of the LACE meta-analysis, it was reported that the 3-year survival rate in the CDDP + VNR arm was 66.7 and $48.2 \%$ for disease stage II and III cases, respectively. In addition, the 3-year survival rate in the JIPANG study was reportedly $83.5 \%$, and the survival rate statistics observed in our study were comparable to those in previous reports, although only a small number of reports could be identified. In this study, the 3 -year RFS by histology was $45.8 \%$ with adenocarcinomas, and $81.3 \%$ with non-adenocarcinomas, indicating a significantly poorer RFS with adenocarcinomas; however, the 5-year OS was $62.5 \%$ with both adenocarcinomas and non-adenocarcinomas, indicating no significant difference in OS. The number of patients with adenocarcinoma and non-adenocarcinoma having disease stages IIA/IIB/IIIA were $6 / 3 / 15$ and $8 / 5 / 3$, respectively. Therefore, the percentage of adenocarcinoma patients with advanced disease stage was higher; moreover, the recurrence rate of adenocarcinoma was high, and RFS was poor. However, OS seemed to be prolonged in patients who responded to treatment, such as EGFR-TKI, administered after recurrence.

Gastrointestinal symptoms, such as nausea, vomiting, and anorexia, as well as kidney damage and bone marrow suppression due to CDDP administration, are all adverse events that can be dose limiting factors, and their control is extremely important for the success of treatment (17). It has been reported that split-dose administration of CDDP provides the same level of efficacy, but with reduced side effects than bulk administration (18-21). In our study, we found that gastrointestinal symptoms and kidney disorders were less severe than in previous reports of bulk administration of CDDP; thus, this treatment has reduced side effects. Furthermore, all patients in this study received inpatient treatments, and were administered $2,000 \mathrm{ml} /$ day of hydration. In recent years, the tolerability and safety of the short hydration method have been reported for bulk administration of CDDP (22), and it is therefore, widely used.
It is highly likely that the split-dose administration of CDDP can be expected to further reduce the amount of hydration and shorten the infusion time, and may be more suitable for outpatient treatment compared to bulk administration. This study is not a clinical trial, but rather is based on routine clinical data. There is little data on postoperative adjuvant chemotherapy using split-dose CDDP + VNR. However, these findings suggest that the treatment is safe, well-tolerated and effective both in patients aged 70 years and older and in patients younger than 70 years. However, as there are several limitations to this study, such as it being a single center study, involving only a small number of patients and it being a retrospective study, it would be ideal to carry out a prospective study to validate the results.

In conclusion, combined CDDP + VNR adjuvant chemotherapy via split-dose CDDP administration is suggested to elicit reduced gastrointestinal toxicities and nephrotoxicity compared to bulk CDDP administration. Our results supported this and showed that the former was sufficiently tolerable, safe and effective. We believe split-dose CDDP + VNR may become a standard adjuvant chemotherapy regimen for NSCLC, but further studies are needed to validate this.

\section{Acknowledgements}

Not applicable.

\section{Funding}

No funding was received.

\section{Availability of data and materials}

The datasets used and/or analyzed during the current study are available from the corresponding author on reasonable request.

\section{Authors' contributions}

YO, NF and HO designed the study. NF, DK, TG, YS, JE, KY and FI performed data collection. NF, HI and $\mathrm{CH}$ analyzed and interpreted the data. NF, HI, CH and DK confirm the authenticity of all the raw data. NF, HI, YO and HO edited and critically reviewed the manuscript for important intellectual content. All authors have read and approved the final manuscript.

\section{Ethics approval and consent to participate}

The present study was approved by the Institutional Review Board (Gifu University Graduate School of Medicine Ethics Committee; approval no. 2021-A055). In view of the retrospective nature of the study, informed consent from the subjects was not mandated.

\section{Patient consent for publication}

Not applicable.

\section{Competing interests}

The authors declare that they have no competing interests. 


\section{References}

1. Sawabata N, Miyaoka E, Asamura H, Nakanishi Y, Eguchi K, Mori M, Nomori H, Fujii Y, Okumura M, Yokoi K, et al: Japanese lung cancer registry study of 11,663 surgical cases in 2004 Demographic and prognosis changes over decade. J Thorac Oncol 6: 1229-1235, 2011.

2. Chemotherapy in non-small cell lung cancer: A meta-analysis using updated data on individual patients from 52 randomised clinical trials. Non-small Cell Lung Cancer Collaborative Group. BMJ 311: 899-909, 1995.

3. Arriagada R, Bergman B, Dunant A, Le Chevalier T, Pignon JP, Vansteenkiste $\mathrm{J}$ and International Adjuvant Lung Cancer Trial Collaborative Group: Cisplatin-based adjuvant chemotherapy in patients with completely resected non-small-cell lung cancer. $\mathrm{N}$ Engl J Med 350: 351-360, 2004.

4. Winton T, Livingston R, Johnson D, Rigas J, Johnston M, Butts C, Cormier Y, Goss G, Inculet R, Vallieres E, et al: Vinorelbine plus cisplatin vs. observation in resected non-small-cell lung cancer. N Engl J Med 352: 2589-2597, 2005.

5. Douillard JY, Rosell R, De Lena M, Carpagnano F, Ramlau R, Gonzáles-Larriba JL, Grodzki T, Pereira JR, Le Groumellec A, Lorusso V, et al: Adjuvant vinorelbine plus cisplatin versus observation in patients with completely resected stage IB-IIIA non-small-cell lung cancer (Adjuvant navelbine international trialist association [ANITA]): A randomised controlled trial. Lancet Oncol 7: 719-727, 2006.

6. Butts CA, Ding K, Seymour L, Twumasi-Ankrah P, Graham B, Gandara D, Johnson DH, Kesler KA, Green M, Vincent M, et al Randomized phase III trial of vinorelbine plus cisplatin compared with observation in completely resected stage IB and II non-small-cell lung cancer: Updated survival analysis of JBR-10. J Clin Oncol 28: 29-34, 2010.

7. Bennouna J, Senellart H, Hiret S, Vaissiere N and Douillard JY: Impact of histology on survival of resected non-small cell lung cancer (NSCLC) receiving adjuvant chemotherapy: Subgroup analysis of the adjuvant vinorelbine (NVB) cisplatin (CDDP) versus observation in the ANITA trial. Lung Cancer 74: 30-34, 2011.

8. Pignon JP, Tribodet H, Scagliotti GV, Douillard JY, Shepherd FA, Stephens RJ, Dunant A, Torri V, Rosell R, Seymour L, et al: Lung adjuvant cisplatin evaluation: A pooled analysis by the LACE Collaborative Group. J Clin Oncol 26: 3552-3559, 2008.

9. Douillard JY, Tribodet H, Aubert D, Shepherd FA, Rosell R, Ding K, Veillard AS, Seymour L, Le Chevalier T, Spiro S, et al: Adjuvant cisplatin and vinorelbine for completely resected non-small cell lung cancer: Subgroup analysis of the lung adjuvant cisplatin evaluation. J Thorac Oncol 5: 220-228, 2010.

10. Ettinger DS, Wood DE, Aisner DL, Akerley W, Bauman JR, Bharat A, Bruno DS, Chang JY, Chirieac LR, D'Amico TA, et al: NCCN guidelines insights: Non-small cell lung cancer, version 2.2021. J Natl Compr Canc Netw 19: 254-266, 2021.
11. Yamaguchi M, Takeo S, Suemitsu R and Matsuzawa H: Feasibility study for biweekly administration of cisplatin plus gemcitabine as adjuvant-chemotherapy for completely resected non-small cell lung cancer. Cancer Chemother Pharmacol 66: 107-112, 2010.

12. Ohe Y, Ohashi Y, Kubota K, Tamura T, Nakagawa K, Negoro S, Nishiwaki Y, Saijo N, Ariyoshi Y and Fukuoka M: Randomized phase III study of cisplatin plus irinotecan versus carboplatin plus paclitaxel, cisplatin plus gemcitabine, and cisplatin plus vinorelbine for advanced non-small-cell lung cancer: Four-Arm cooperative study in Japan. Ann Oncol 18: 317-323, 2007.

13. Kenmotsu H, Yamamoto N, Yamanaka T, Yoshiya K, Takahashi T, Ueno T, Goto K, Daga H, Ikeda N, Sugio K, et al: Randomized phase III study of pemetrexed plus cisplatin versus vinorelbine plus cisplatin for completely resected stage II to IIIA nonsquamous non-small-cell lung cancer. J Clin Oncol 38: 2187-2196, 2020.

14. Kenmotsu H, Ohde Y, Wakuda K, Nakashima K, Omori S, Ono A, Naito T, Murakami H, Kojima H, Takahashi S, et al: Survival data for postoperative adjuvant chemotherapy comprising cisplatin plus vinorelbine after complete resection of non-small cell lung cancer. Cancer Chemother Pharmacol 80: 609-614, 2017.

15. Furukawa N, Kawaguchi R and Kobayashi H: Use of high-dose cisplatin with aprepitant in an outpatient setting. Eur J Cancer Care (Engl) 21: 436-441, 2012.

16. Sonobe M, Okubo K, Teramukai S, Yanagihara K, Sato M, Sato T, Chen F, Sato K, Fujinaga T, Shoji T, et al: Phase II study of adjuvant vinorelbine and cisplatin in Japanese patients with completely resected stage II and III non-small cell lung cancer. Cancer Chemother Pharmacol 74: 1199-1206, 2014.

17. Ng TL, Hutton B and Clemons M: Chemotherapy-induced nausea and vomiting: Time for more emphasis on nausea? Oncologist 20: 576-583, 2015.

18. Takiguchi Y, Moriya T, Asaka-Amano Y, Kawashima T, Kurosu K, Tada Y, Nagao K and Kuriyama T: Phase II study of weekly irinotecan and cisplatin for refractory or recurrent non-small cell lung cancer. Lung Cancer 58: 253-259, 2007.

19. Ozawa Y, Inui N, Naitoh T, Yasuda K, Nagayama M, Shirai T, Suganuma H, Fujii M, Nakamura H, Suda T and Chida K: Phase II study of combination chemotherapy with S-1 and weekly cisplatin in patients with previously untreated advanced non-small cell lung cancer. Lung Cancer 63: 68-71, 2009.

20. Hiramatsu A, Iwasaki Y, Koyama Y, Tamiya N, Hosogi S, Nakanishi M, Kohno Y, Ueda M, Arimoto T and Marunaka Y: Phase II trial of weekly gemcitabine and split-dose cisplatin for advanced non-small-cell lung cancer. Jpn J Clin Oncol 39: 779-783, 2009.

21. Berardi R, Porfiri E, Scartozzi M, Lippe P, Silva RR, Nacciarriti D, Menichetti ET, Tummarello D, Carle F, Piga A and Cellerino R: Elderly patients with advanced non-small cell lung cancer: A phase II study with weekly cisplatin and gemcitabine. Oncology 65: 198-203, 2003.

22. Horinouchi H, Kubota K, Itani H, Taniyama TK, Nakamichi S, Wakui H, Kanda S, Nokihara H, Yamamoto N, Sekine I and Tamura T: Short hydration in chemotherapy containing cisplatin ( $\geq 75 \mathrm{mg} / \mathrm{m} 2$ ) for patients with lung cancer: A prospective study. Jpn J Clin Oncol 43: 1105-1109, 2013. 